\title{
Aufruf zur Teilnahme am Science Slam Kinderradiologie 2020
}

Liebe Kolleginnen und Kollegen,

auf unserer diesjährigen Jahrestagung der Gesellschaft für Pädiatrische Radiologie in Essen erwartet Sie ein besonderes Highlight. Erstmals in der Geschichte unseres Kongresses veranstalten wir einen Science Slam!

Vielleicht haben Sie eine solche Veranstaltung schon einmal besucht: Wie in einer wissenschaftlichen Lehrveranstaltung präsentiert der/die Vortragende ein wissenschaftliches Thema, bringt es aber knapp, witzig und perfekt einstudiert auf den Punkt. Und es gibt auch noch einen Wettbewerbsgedanken dabei: Es entscheiden nämlich die Zuschauer, welcher der 4 oder 5 Vortragenden des Abends sie am meisten gepackt hat.

Science Slam in der Kinderradiologie?

Wir möchten am Donnerstag, 01.10.2020 ab 18:00 Uhr zeigen, dass das geht!
Zum Mitmachen aufgerufen sind alle Kolleginnen und Kollegen, die Spaß an der Lehre haben und außerdem Lust darauf, ein neues und herausforderndes Vortragsformat auszuprobieren - ganz gleich ob als Student oder als Institutsleiter!

Wenn Sie Interesse haben oder Kolleginnen und Kollegen kennen, für die der Science Slam eine Bühne sein könnte: Schreiben Sie mir! Wir werden nicht alle Bewerber berücksichtigen können, da die Kandidaten vor ihrem Auftritt ein intensives Training bei einer Schauspiellehrerin erhalten werden. Allen angenommenen Bewerbern hingegen garantieren wir eine intensive und spannende Vorbereitungszeit.

\section{Und dem Publikum eine kurzweilige und höchst attraktive Präsentation unseres Fachs Kinderradiologie!}

Ich bin gespannt auf Ihre Bewerbungen bis zum 20. Mai 2020!

Sie erreichen mich unter bernd.schwei ger@uk-essen.de.

Mit kollegialen Grüßen

Dr. Bernd Schwaiger

Kongresspräsident

Universitätsklinikum Essen

Alle Informationen und Anmeldung zur 56. Jahrestagung vom 30.09.03.10.2020 in Essen unter www.gpr-jahrestagung.de.

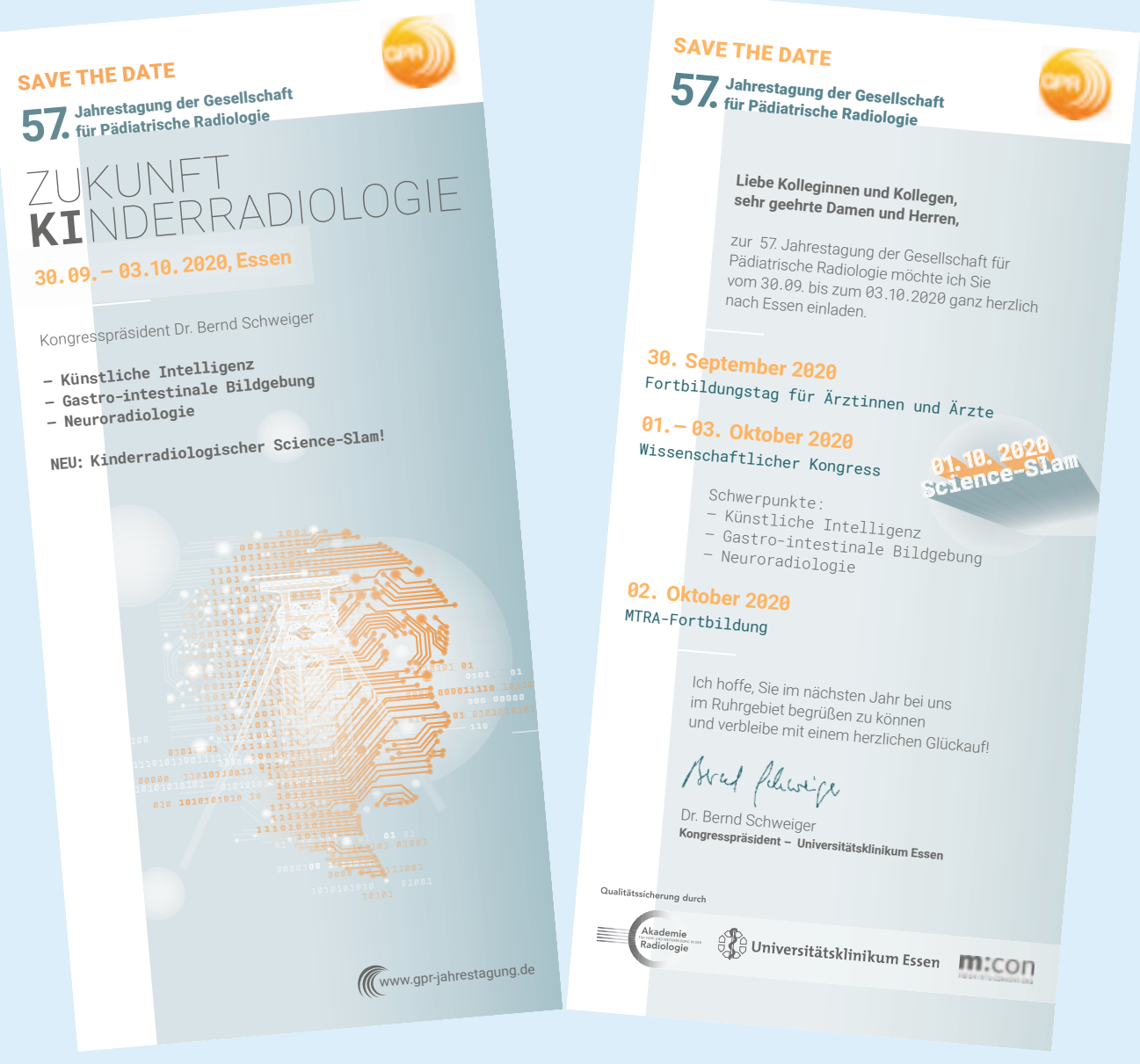

